\title{
1982 PROGRAM CHAIRMEN
}

The program at this year's Annual meeting, to be held in Boston November 1 - 4, looks to be especially stimulating - and this is no

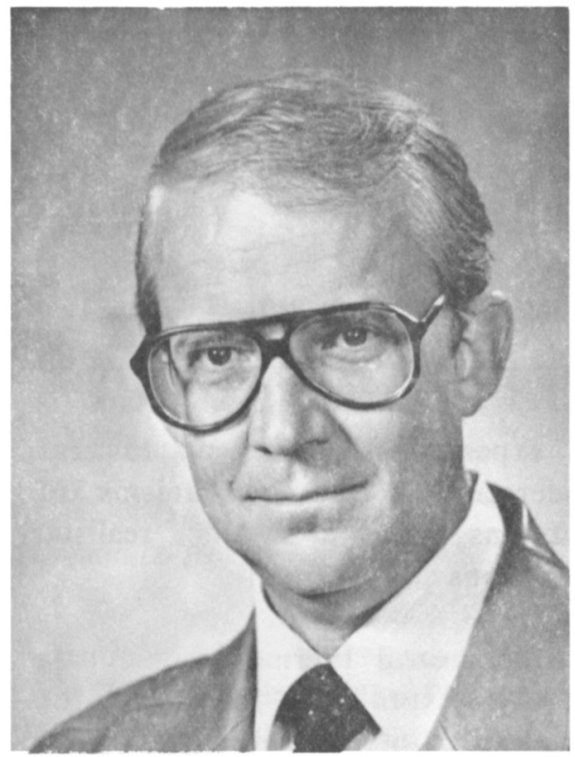

\section{LYNN A. BOATNER}

Boatner was trained as a physicist, taking his undergraduate degree at Texas Tech University and is advanced degrees at Texas Tech and Vanderbilt University, which granted him the Ph.D. in 1966.

While engaged in study of the growth and properties of various single crystals, Boatner performed investigations of the intermediate Jahn-Teller effect that resulted in the first observations of the static to dynamic effect at low temperature. He holds patents for a light sensitive Gunn-effect device and a method of mm-wave detection.

Most recently, Boatner has investigated the science of nuclear waste forms, contributing to the Society's $1981 \quad$ International Symposium on the Scientific Basis for Nuclear Waste Management, and in materials preparation, characterization and crystal growth. accident -- the organizational skills, demanding requirements and diplomacy of three exceptional materials scientists have been focused

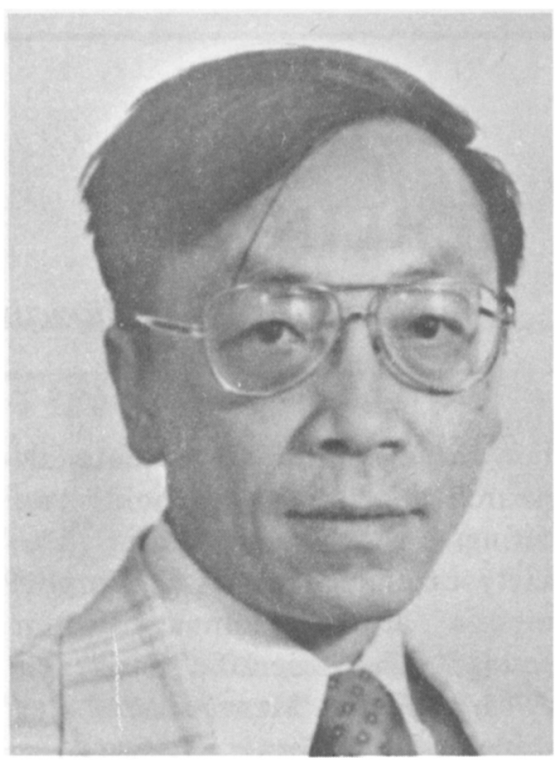

\section{LEROY L. CHANG}

Born in Honan, China, Chang did his undergraduate work at Taiwan University, taking advanced degrees from the University of South Carolina and Stanford University, which granted him the Ph.D. in 1963. A student of electrical engineering, Chang joined the Thomas J. Watson Research Center of the International Business Machines Corporation, where he became Manager of semiconductor microstructures in 1975.

Chang's principal research interests cover materials, physics, and devices He has worked in diffusion, tunneling spectroscopy, field effect and interface properties. It was he who first synthesized and demonstrated the formation of semiconductor superlattices by molecular beam epitaxial techniques. He has pursued, since then, investigations of such microstructures. Both the material aspects of epitaxial deposition and the physical aspects of the electrical properties of the product layers have received his attention. on it for nearly a year. They bring to bear a broad spectrum of experience and interests. The Society appreciates their dedication and diligence.

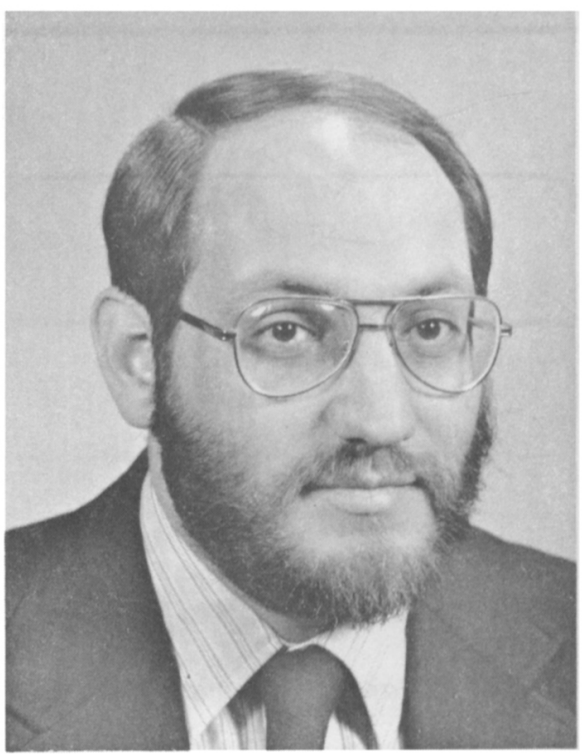

\section{ELTON N. KAUFMANN}

Kaufmann joined the Lawrence Livermore Laboratory of the University of California after serving thirteen Years on the technical staff of Bell Laboratories. At Livermore he is a member of the Materials Sciences Division, and currently pursues research in the areas of nuclear spectroscopy, hyperfine interactions ion-solid interactions, and directed energy processing of materials.

Kaufmann did his undergraduate work at Rensselaer Polytechnic Institute and took his Ph.D. in physics from the California Institute of Technology. Very active in the affairs of the Society, he chaired the symposium on "Nuclear and Electron Resonance Spectroscopies Applied to Materials Sciencen at the 1980 Annual Meeting. $\mathrm{He}$ is currently the chairman of the Society's Corporate Participation Committee. 